\title{
RISK BEHAVIOR AS A REACTION ON UNCONTROLLABLE STRESS
}

\author{
Alla V. Shaboltas \\ St.-Petersburg State University \\ St.-Petersburg \\ Dmitry A. Zhukov \\ Pavlov Institute of Physiology \\ St.-Petersburg
}

\begin{abstract}
Displacement reaction is a universal behavioral reaction for stressful situation. Displacement behavior becomes more probable under uncontrollable stress. Very often human displacement behavior is revealed in different forms of risk behaviors. Many forms of risk behavior are deviant and asocial. The essay reviews the significance of uncontrollable social stress management in humans. Importance of studies on uncontrollable stress for prevention of displacement and risk behaviors is discussed.
\end{abstract}

Keywords: risk behavior, stress, health psychology, coping.

A problem of risk and prevention of human risk behavior is one of the major problems in health psychology. In this essay risk is understood as the possibility of negative health outcomes occurring as a result of specific behavior practices. Risk behavior patterns can be basic for a lot of diseases. Smoking, alcohol and drug use, uncontrollable sexual behavior and more seldom professional overwork, high functional and psychic loads leading to somatic and mental diseases are mentioned as the examples of health risk behaviors (Shaboltas, 2004).

Theoretical concepts explaining the mechanisms of risk behaviors are based mainly on social-cognitive approach (Bandura, 1986). According to this approach behavior is a derivate of two interdependent and inter-conditioned factors - external and internal. Age-related and personality characteristics, specific character of biological, emotional and cognitive processes, attitudes and beliefs, subjective assessment of vari- 
ous behaviors riskiness are considered as internal factors. Psychologists pay special attention to studying correlates of risk behaviors. One of the best investigated personal characteristics associated with susceptibility to risk-taking is sensation seeking (Zuckerman, 2006). This characteristic of personality determines individual ways of coping with everyday routine boredom, as well as adventurism in different spheres of life. A widespread form of high risk predisposition is taking up "extreme" kinds of sport. Extremeness is considered as high possibility of getting harm in case of failure. Sport psychologists face the fact that people's motivation to go in for such sports is connected with their general susceptibility to risk-taking. A person striving for risk in one situation will also strive for risk in other situations. Extreme sports as substitution let such people satisfy this need and consume their high energy potential. In conditions of adequate safety level this kind of leisure activities could be considered as prevention of risk behaviors in other areas of life. All people can be placed on the continuum with the poles of two types: "risky" and "cautious". Risky people tend to influence others, to strive for leadership; they have a high level of aspiration. Cautious people prefer to obey; they are more conservative and indecisive. The other individual characteristic associated with risk behavior is a belief (attitude) towards personal future. In everyday life such beliefs are divided into optimistic and pessimistic. People with positive views about their future use more measures focused on providing safety and health care than people who demonstrate negativism. Such qualities as impulsivity, achievement motivation and low self-control are also referred to psychological risk correlates.

Individual ways of coping and resistance in stressful situations are particularly topical for studying and correction. A stressful situation is objectively an external factor of personal behavior. Thereby, a choice of individual strategies of stress management is highly determined by previous personal experience and individual psychological characteristics. Such risk behavior models as alcohol use, drug use, unsafe sex, adventurist strategies and tactics in professional activity are very often conditioned by stress avoidance and a low level of personal adaptation to stress.

The concept "stress" was introduced by Hans Selye who understood it as nonspecific adaptive systematic response reaction of human or animal to any stimuli (Selye, 1956). Nowadays it is emphasized that stress is a response reaction to new stimuli (Zhukov, 2007). It means that a stress- 
ful reaction develops in an organism when it faces unknown conditions or problems. In a new situation without a habitual, ready i.e. formed earlier program of action human or animal uses the so called displacement reactions at behavioral level. The displacement reaction is a behavioral reaction which was formed in other situations in order to satisfy other needs and it does not correspond to the actual need (Tinbergen, 1951). If the motivation which was formed on the ground of need caused by changes in the environment is strong enough and there is no ready behavioral pattern people use behavioral programs which in this context are unconstructive

We could demonstrate this using some concrete examples from our lives and counseling practice. Food, sexual and aggressive behaviors are common and are the most spread types of personal behavior. In usual "normal" conditions these behaviors are focused on satisfying vital body and personal needs - need for food, sexual need, need for safety, control, etc. Another picture is observed in new unusual situations when people use habitual behavior patterns not for satisfying a specific need but in the first place to manage stress. In this case we most often deal with risk behavior i.e. with the behavior which can be dangerous for physical or psychological health. Human ability to cope with difficulties and new problems with the help of constructive strategies is an important protective factor against stress development. It very often occurs that people use unconstructive strategies. For example, it is well known that many people tend to overeat in troublesome situations. To be more exact, when there is no ready decision for the occurred troubles a person - absolutely unconsciously - eats food in the amounts which are much higher that he or she needs to deal with hunger. Practically all people suffering from alcohol or drug addiction had stress as one of the major factors in their addiction development history. People who practice regular sexual life show higher sexual activity in a stressful situation (Svyadosh, 1988). The seduction of widow next to her husband's coffin described in Shakespeare's Richard III is a classic example of sexual activity as a behavior in stressful situation.

Risk behavior can have dangerous consequences not only for a person themselves but also for surrounding people. People using open aggressive behavior as a behavioral pattern are the most socially dangerous. To illustrate this we can consider the behavior of soldiers who participated in military actions. In this case aggressive behavior focused on the sur- 
rounding people is one of the components of posttraumatic stress which was caused by soldiers' presence in unusual conditions of the real threat to their own lives (Tarabrina, 2009). In war conditions such a behavior is normal and adequate because it allows a person to survive. The longer is the period a person stays in such conditions, the higher is the possibility of aggressive behavior to become habitual. For such people harming another person will become a habitual form of behavior. Returning back to civil life and getting into stressful situation not connected with a direct threat to life and health people who participated in military actions often react as they are used to - with aggressive behavior up to injuring other people.

Two types of stress are distinguished - controllable and uncontrollable stress. An uncontrollable stress is defined by unpredictable, unavoidable or inadaptable stressful influence. Both types of stress can cause both human and animal risk behaviors. But still the uncontrollable stress is especially dangerous for human health and in particular for his social integration. The term "uncontrollability" was for the first time introduced by the American psychologists Overmier and Seligman (Overmier \& Seligman, 1967). It should be noted that animals are generally used as the objects of experimental research of behaviors in stress. Ethical requirements for doing research on human most often make such experiments impossible on account of potential health risks.

During their experiments Overmier and Seligman irritated dogs' paws with electric shock despite the animals' conditional reflex reaction was correct or incorrect. However, the first experiment which showed the destructive influence of uncontrollable situation on animals' health is the work carried out in Pavlov's laboratory in St. Petersburg (ShengerKrestovnikova, 1921). In this experiment the dog had to differentiate an ellipse from a circle. It was easy with the axis ratio 1:2. But when axis ratio became 8:9 the dog was not able to distinguish an ellipse from a circle. After three weeks of the unsuccessful attempts to distinguish the stimulus which was followed by a reward from the "blank" stimulus the dog got motor ("constantly excited"), emotional ("was constantly anxious") and cognitive ("all earlier formed conditioned reflexes disappeared") disorders.

It is very notable that not only pain but also other aversive stimuli were not used in this experiment. The dogs were not hungry. Every animal got food in the animal house in the evening independently of how 
successfully it managed the task during the experiments in the afternoon. The animal's behavioral disorders were caused only by the impossibility to predict changes in the environment. The dog could not predict if it would get a food reward or not.

These experiments demonstrated that stress situation associated with uncontrollability and, in particular, unpredictability leads to behavioral disorders. Such behavioral disorders are called "learned helplessness" whose symptoms to a great degree are similar to basic symptoms of depression and personal feeling of uncertainty (Zhukov, 2007).

The uncontrollable stress plays a enormous role in our life. People and animals subject to uncontrollable influence demonstrate among other symptoms a rapid weakening of personality power and will. Consequently, they become more controllable. Such methods are actively used in animal training. For instance, falconry - an old Russian leisure activity - required a large amount of tamed birds. A caught falcon got no food during three days before training. As a result of uncontrollable stress the bird became controllable. The same situation to which the animal could not adapt was created for horses during the breaking in.

However, the main field of uncontrollable stress implementation is making a person more controllable i.e. controlling their behavior. People constantly feel uncontrollable social pressure from surrounding people and also create uncontrollable situations for others. A person in a state of learned helplessness loses his/her ability and above all the desire to estimate events and to make own decisions. A person stops feeling control over his/her life and begins to rely completely on other people's opinion. It is easy to rule a person with a weakened will so forming of learned helplessness by means of uncontrollable situation is an old and widespread method of behavior manipulation.

The use of violence in various forms - emotional, physical and sexual - against other people is one of the dramatic examples of acquired learned helplessness. In the families where both emotional and physical violence takes place regularly suffering family members, most often women and children, very often demonstrate all the signs of learned helplessness - lack of confidence, loss of control over their lives, decrease of self-esteem, loss of personal opinion. As a consequence of being in loss of control situations related to violence people appear to be unable to resist and protect themselves. Such facts often give birth to idle talk that if "a woman neither leaves her husband-violator nor resists 
sexual violence it means that she likes it". The research of psychological characteristics of the victims of different kinds of violence discover a specific symptom-complex of psychological qualities which is called "victim personality" and it means that a person becomes more vulnerable as an object for violence because he/she demonstrates the signs of learned helplessness. There is a whole scientific branch - victimology which studies victims of offences (Rivman, 2002). Indeed, a person who behaves and looks unconfidently is regarded by a potential violator, sometimes quite unconsciously, as a more attractive or possible victim of violence. In most cases when a violator uses violence to satisfy the need in control he chooses people who are in lower position or status. There is a joke describing such state of affairs: "A chief swore at an employee at work, the employee came home and swore at his wife, the wife swore at her son who came from school, the son in his turn kicked a dog, the dog ran out into the street, and bit a stranger - the employees chief". From our point of view, very often victim characteristics or vulnerability is a sign of learned helplessness.

An appalling example of forming learned helplessness in big groups of people is "labor camps" in fascist Germany which existed until the beginning of World War II (Bettelheim, 1943). In these camps people were reeducated through unpredictable stressful influence. The camp regulations frequently changed and the prisoners were not informed about the changes in advance. Meanwhile, any violation of the rules was cruelly punished. Besides, a quite rough method of "irrationalization" was used: the prisoners were made to do meaningless work. For example, they were not only made to dig holes and to fill them up again - the prisoners could explain it by the sadism of a concrete guard - but also to listen repeatedly to the camp regulations which as well were displayed on every pole. As a result, the prisoners like the Shenger-Krestovnikova's dog that became neurotic in fruitless attempts to understand the world's laws acquired learned helplessness in no more than several months. They were set free as new people - people without own initiative, activity and life energy, and consequently, easy controllable.

The effective use of uncontrollable situation in order to create learned helplessness and to induce a individual controllability is described by W. Shakespeare in The Taming of the Shrew which is considered to be "a masterpiece of comedian art". One of the characters Petruchio himself and with the help of his servants constantly humiliates his wife, starves 
her and makes her do stupid things and talk nonsense. Finally, a willful Katherina turned into a creature without any own will.

It is worth to note that Katherina's ordeals as a critic writes "...will end not with grief and captivity but with a big human happiness" (Shakespeare, 1958). And, indeed, we can't find any hint of suffering in tamed Katherina's words and behavior. Actually, a subjective feeling of happiness as a way to cope with uncontrollable stress can follow learned helplessness and be its big advantage as a method of controlling people. The satisfaction of camp prisoners with thier new passive relation to the world is mentioned in Bettelheim's work as well (Bettelheim, 1943).

An important methodic moment should be emphasized in Petruchio's behavior aimed at forming learned helplessness in Katherina's character. He humiliates Katharina not because she is willful but without any cause. Due to unpredictability of the influence, Katharina's negative emotions are not the reaction to this or that undesired behaviors, these emotions appear at random. It is the lack of any causal relation between the object's behavior and the influence unpleasant for him which is the essential condition for the situation to become uncontrollable. If the punishment, even rather rough, follows certain acts, the subject will learn to avoid such behaviors. The general controllability of behavior will not increase because in this case not the learned helplessness but the conditioned reflex of avoiding certain situations forms. That is why in the process of animal training, for example, of dogs the instructors insist that the owners perform punishment straight after a misdeed and in no case postpone it. Such recommendations can also be given to the parents who sometimes after the child's misdeed postpone an unpleasant talk or other punishment to a more suitable moment, for example, when other people will not see it or the parents just do not explain what they punish for.

In this way parents create uncontrollable stress for their own children. If the parents punish their children without explanations, they form the learned helplessness in the child.

As the example we would like to mention a case from our counseling practice while working with a boy in the crisis centre for victims of violence. A 15-year-old teenager had serious psychological problems and learned helplessness which was caused in particular by his father who practiced the so called "Saturday beatings" of his daughter and son for all possible misdeeds which happened during the week and as preventive measures for the future. 
Understatement of marks for naughty school-children not because of their knowledge but because of their bad behavior is another example of negative pedagogic influences. The evident contradiction between the answer's quality and the received mark, fruitless attempts to understand what the teacher wants cause in the naughty child a depressive-like state which is characterized by the change in motor activity as one of it's peculiarities. Finally, such a pupil stops moving and talking at the lesson. In such a way a teacher reaches the desired goal and achieves control in the class. Unfortunately, a rough prescriptive model of relationships with children at schools and in other educational establishments is still dominant and wrongfully widely used in Russia. It happens because teachers consider their main task to create conditions when they can control children, not help them develop as free persons.

Uncontrollable stress is dangerous not only because it can harm a subject's psychical health directly. The fact is that the uncontrollability of situation is a subjective factor. The degree of the situational controllability is defined not only by real, objective chances to influence getting reward or to avoid punishment. The feeling of control over the situation depends on individual perception of the situation. Let us consider another example of experiments on animals. A rat which receives unpredictable and unavoidable electric shocks gets learned helplessness. If two rats in one cage are influenced in this way they begin to fight and, as a result, do not develop learned helplessness (Zhukov \& Vinogradova, 1998). In this case, agonistic interaction provides the animals with a subjective feeling of control over the situation. In his article where he analyzes the psychological pressure on labor camp's prisoners Bruno Bettelheim recommends this behavioral strategy to all who happened to be in such a situation (Bettelheim, 1943). To cope with uncontrollable stress one should create the illusion of controllability i.e. one should do all the things which are allowed. If it is allowed to clean the teeth one should clean the teeth. If physical exercises are allowed one should do squats, press-ups, etc. The same strategy is recommended during the work with victims of violence in case they have developed learned helplessness. For example, it is suggested first of all to choose a very easy kind of activity which can be easily accomplished by the victim themselves - to do something easy not combined with cooperation with other people or solving difficult social problems (to take care of oneself, 
to find some pleasant hobby). As self-confidence increases in the process one can gradually reach the feeling of control over one's life.

Unfortunately, it often happens that people and particularly children living under teachers, parents or other dominating persons strain choose various risk behaviors in order to create subjective controllability. In order to cope with stress and to form the feeling of control over the situation they practice violence, fights, smoking, psychoactive substances. Qualitative data analysis of in-depth interviews conducted in a group of 520 injection drug users - participants of HIV prevention project in St.-Petersburg - have demonstrated a high level of correlation between the first drug experience and regular drug use with dominant style of relationships in families and schools. Also the majority of drug users demonstrate the low level of effective stress management (Shaboltas et al., 2006).

The wide spread practice of dominant relationships between people including relationships between teachers and students using the strategy of creating uncontrollable situations in order to establish a certain level of student management is a double danger. On the one hand, long-term uncontrollable stress leads to depressive-like disorders (Cole et al., 2007; Dettling et al. 2007; McKean, 1994). And on the other hand, people often use various risk behaviors in order to cope with stress and to form a subjective feeling of control over the situation in everyday life (Sacco et al., 2007; Steptoe \& Marmot, 2003; Weden et al., 2006).

Nowadays, serious psychological and organizational efforts of different specialists to develop and implement effective preventive measures for reducing the level of uncontrollable stress in educational institutions in order to prevent negative consequences of stress such as depression, anxiety and risk behaviors in students are required in Russia. The effectiveness of such programs focused on depression and anxiety was demonstrated in a longitudinal studies conducted in other countries, for example in the USA (Gillham et al., 2007). The actual task for Russian researchers is to develop and evaluate the efficiency of prevention programs focused on different risk behaviors used by teens and adolescents. Obviously, prevention efforts should combine definite recommendations and methods on educational process management, teacher/student and parent/child relations based on humanistic paradigm and be focused first of all on the development and increase of individual personal resources in every child. 


\section{References}

Bandura, A. (1986). A social foundation of thought and action: A social cognitive theory. Prentice-Yall, Englewood Cliffs, NJ.

Bettelheim, B. (1943). Individual and Mass Behavior in Extreme Situations. Journal of Abnormal and Social Psychology, 38, 417-452.

Cole, D.A., Warren, D.E., Dallaire, D.H., Lagrange, B., Travis, R., \& Ciesla, J.A. (2007). Early predictors of helpless thoughts and behaviors in children: developmental precursors to depressive cognitions. Clin Child Psychol Psychiatry, 12(2), 295-312.

Dettling, A.C., Schnell, C.R., Maier, C., Feldon, J., \& Pryce, C.R. (2007). Behavioral and physiological effects of an infant-neglect manipulation in a bi-parental, twinning primate: impact is dependent on familial factors. Psychoneuroendocrinology. 32(4). 331-349.

Gillham, J.E., Reivich, K.J., Jayco, L.H., \& Seligman, M.E.P. (2007). Prevention of depressive symptoms in schoolchildren: Two-year follow-up. Psychological Science, 6, 343-351.

McKean, K.J. (1994). Using multiple risk factors to assess the behavioral, cognitive, and affective effects of learned helplessness. J. Psychol., 128(2), 177-183.

Overmier, J.B., \& Seligman, M.E.P. (1967). Effects of inescapable shock upon subsequent escape and avoidance learning. J. Comp. Physiol. Psychol., 63, 28-33.

Rivman, D.V. (2002). Kriminal'naja viktimologija [Criminal victimology]. St.-Petersburg: Piter.

Sacco, K.A, Head, C.A, Vessicchio, J.C., Easton, C.J., Prigerson, H.G., \& George, T.P. (2007). Adverse childhood experiences, smoking and mental illness in adulthood: a preliminary study. Ann. Clin. Psychiatry, 19(2), 89-97. Erratum in: Ann Clin Psychiatry, 2007, 19(3), 211.

Selye, H. (1956). The Stress of life. New York: McGraw-Hill.

Shaboltas, A.V. (2004). Riskovoe povedenie [Risk behavior]. In A.A. Krylov, \& S.A. Manichev (Eds.), Psikhologija [Psychology]. Moscow: Prospect.

Shaboltas, A.V., Toussova, O.V., Hoffman, I., Heimer, R., Verevochkin, S.V., Ryder, R.W., Khoshnood, K., Perdue, T., Masse, B.R, \& Kozlov, A.P. (2006). HIV prevalence, sociodemographic, and behavioral correlates and recruitment methods among injection drug users in St.-Petersburg, Russia. J.AIDS, 41(5), 657-663.

Shakespeare, W. (1958). Ukroschenie stroptivoj [The Taming of the Shrew]. Moscow: Iskusstvo.

Shenger-Krestovnikova, N.R. (1921). On the visual stimuli differentiation. Ann. of P.F.Lesgaft Pedagogical Scientific Institute, 3, 1-41.

Steptoe, A., \& Marmot, M. (2003). Burden of psychosocial adversity and vulnerability in middle age: associations with biobehavioral risk factors and quality of life. Psychosom. Med. 65(6),1029-1037. 
Svyadozh, A.M. (1988). Zhenskaja seksopatologija [Women's sexopathology]. Moscow: Medicina.

Tarabrina N.V. (2009). Psihologija posttravmaticheskogo stressa [Psychology of post-traumatic stress]. Moscow: Kogito-center.

Tinbergen, N. (1951). The Study of Instinct. Oxford: Clarendon Press.

Weden, M.M., Astone, N.M., \& Bishai, D. (2006). Racial, ethnic, and gender differences in smoking cessation associated with employment and joblessness through young adulthood in the US. Soc. Sci. Med., 62(2), 303-316.

Zhukov, D.A. (2007). Biologija povedenija. Gumoral'nye mehanizmy [Biology of behavior. Humoral mechanisms]. St.-Petersburg: Rech.

Zhukov, D.A., \& Vinogradova, E.P. (1998). Agonistic behavior during stress presents the development of learned helplessness in rats. Neurosci Behav. Physiol., 28(2), 206-210.

Zuckerman, M. (2006). Sensation Seeking And Risky Behavior. American Psychological Association (APA). 